Article

\title{
Me and My New World: Effects of a School Based Social-Emotional Learning Program for Adolescents in Panama
}

\author{
Ana Belinda Araúz Ledezma *, Karlijn Massar ${ }^{\mathbb{D}}$ and Gerjo Kok ${ }^{\mathbb{D}}$ \\ Work \& Social Psychology, Maastricht University, P.O. Box 616, 6200MD Maastricht, The Netherlands; \\ karlijn.massar@maastrichtuniversity.nl (K.M.); g.kok@maastrichtuniversity.nl (G.K.) \\ * Correspondence: ana.arauzledezma@maastrichtuniversity.nl
}

Received: 30 July 2020; Accepted: 8 September 2020; Published: 15 September 2020

\begin{abstract}
Gender inequalities still affect the health and well-being of young people worldwide. Given the apprehensions among government and educators in a conservative context like Panama to implement comprehensive sexual education, there is a need for other educational efforts to stimulate healthy and respectful intimate relationships between adolescents. This article examines to what extent a newly developed Social-Emotional Learning (SEL) program, Me and My New World, provides a context in which students can learn to recognize and manage emotions, to care about others and themselves, make responsible decisions, develop social awareness. The program could additionally facilitate behavioral changes of young people towards more gender equality. Specifically, we focused on equal gender roles, equal rights in relationships and nonviolent problem solving, and present the qualitative effect evaluation among adolescents in Panama. The findings suggest that SEL-based lessons might broaden views on how young people experience the process of exploring identity formation, how assumptions of inequalities can be recreated through the lessons, and that SEL can emphasize the significance of choice and decision-making in interpersonal relationships. The perspectives, needs, and limitations highlighted by the adolescents living in a conservative context are highly valuable for improving future learning strategies for the development of healthier relationships.
\end{abstract}

Keywords: equal relationships; social-emotional learning; gender equality

\section{Introduction}

Relationships between women and men are deeply influenced by gender social norms and the socially developed gender identities of women and men [1,2]. Gender is defined as "the roles, behaviors, activities, attributes and opportunities that any society considers appropriate for boys and girls, and men and women" (p. 644) [3]. Unequal gender relations are often reproduced in very subtle ways, affecting men and women's identities, leading to "behavior, choices and judgments that tend to 'normalize' gender inequalities" (p. 81) [4]. Equal rights, opportunities and responsibilities for women and men, boys and girls, as well as equal economic participation and decision-making, known as gender equality [5], involve factors as power, agency and socially accepted gender cultural norms. Equal relationships consist of both partners considering the different needs and interests of men and women, involving equal allocation of power and resources [6]. Unequal gender behaviors, for example violence against women, and violations of women and girls' sexual and reproductive health and rights, prevail worldwide. 
Over the past 15 years, stimulated by the UN Millennium Development Goals (MDG), the Education for All (EFA) goals and the latest UN Sustainable Development Goals (SDG), governments and international NGOs have promoted a gender equality agenda based on girls' rights for and access to school. However, although more girls now access education, this approach-focusing mainly on rights to education and access to school—has been debated, as evidence shows limited and low results in the overall progress of women towards equal rights and opportunities throughout their lives, both at national and international levels [7]. In Panama, where several legal reforms towards commitment to international agreements on protection of Women's Rights and Gender Equality have been implemented, young people are nevertheless faced with multiple challenges related to unequal gender relations and behaviors. Teenage pregnancies, HIV infections and violence against women and girls grow exponentially. In 2017, an average of 30\% of pregnant women were girls between 10-19 years old [8]. Scholars recognize multiple causes, such as the absence of comprehensive sexuality education (CSE), a culture of 'machismo', religious beliefs, and low socio-economic status for a majority of the population [9].

Since gender inequalities and their mental and physical consequences are recreated by social processes that coordinate interactions among women, men, boys and girls, achieving equality of women and men will require additional interventions to current laws and institutional policies [10]. A focus on individual relations between women and men [11], might urge transformative strategies. Vaughn [12] stresses that "legal rights and access to institutions are crucial starting points for gender equality, but they are not sufficient in themselves to undo many of the facets of gender inequalities which are evident in the ways in which social interactions reproduce gender inequalities" (p. 4) [12]. Social-Emotional Learning (SEL), "the process through which children and adults acquire and effectively apply the knowledge, attitudes and skills necessary to understand and manage emotions, set and achieve positive goals, feel and show empathy for others, establish and maintain positive relationships and make responsible decisions" (p. 9) [13], might encourage changes in gender unequal behaviors of adolescents in Panama.

Research has demonstrated multiple positive outcomes of SEL-programs related to interpersonal violence, bullying, drug use, social isolation, health, and well-being, disruptive behaviors, and educational achievement [14,15]. SEL offers a framework to explore gender issues, e.g., conceptions of the self (gender identities), patterns that promote stereotyping, unequal relationships (attitudes, beliefs), the extent of self-determination (choice, decision-making), enhancement of agency and active participation. Although most of SEL-programs have been implemented in the United States and Northern countries, socio-emotional skills lessons were adopted worldwide in school classrooms [16]. As knowledge advances on what, how, and for whom SEL works, and under which ecological conditions [16], experiences in developing countries such as Panama are especially relevant. Knowledge about the influence of social norms, religious beliefs, race, ethnicity, as well as different educational systems and pedagogies on adolescents' interpersonal relationships in these countries is lacking. Evidence about the benefits of SEL on gender issues is still insufficient. Some findings are related to teenage pregnancy prevention, the impact of programs by gender, recognition of different needs of boys and girls, and the ratio of participants by gender $[17,18]$.

Education remains a crucial arena where the reproduction of gender roles can be challenged [19]. It plays a role in transforming norms and dominant ideas about what are appropriate roles and activities for women/girls and men/boys [12,20,21]. Since children and adolescents spend a great part of their time at school, educational settings can provide opportunities in the process of deconstructing unequal gender identities, either by structural changes (e.g., mixed gender classes) or by adjusting curriculum and learning practices. Engaging teachers and stimulating the exploration of their views on gender norms and practices might increase ownership towards gender transformations [12]. SEL could facilitate the provision of gender equality lessons and healthy interpersonal relationships through schools. 
The inclusion of a SEL-based lesson plan in secondary schools in Panama might provide an alternative route to achieving more gender equal relationships among adolescents, characterized by mutual respect. A needs assessment among different stakeholders in Panama [22], such as parents, teachers, government and NGO representatives, revealed that these stakeholders recognized the importance of interpersonal skills development of adolescents. Moreover, they agreed that educational programs based on SEL could be a suitable option to start improving personal capacities of young people towards more equal and respectful personal relationships. These results were used to support the development and implementation of the school based SEL-program Me and My New World (MANW) in Panama [22]. The lessons in this program focus on the promotion of equal gender behaviors: equal roles, equal rights in relationships and nonviolent problem solving among adolescents. We present the first effects of a pilot implementation of the MANW program among adolescents from Boquete, Panama.

The significance of the current study lies on broadening insights regarding adolescents' views and experiences in personal relationships, and the potential of social-emotional capacities development lessons that might positively influence their decisions and behaviors, and ultimately reduce health risks, especially teenage pregnancies. The adolescents in the current research were interviewed before and after their participation in the MANW program, and they were questioned about these issues to determine the effect of the program on their attitudes and beliefs regarding gender equal and respectful interpersonal relationships.

\section{Methods}

\subsection{Study Setting}

This evaluation examines the perceived effects of the MANW program to the promotion of gender equality among young people in Panama. Approval was given by the Ethics Committee of Psychology and Neuroscience at Maastricht University. The Ministry of Education of Panama, through the regional office in David, authorized this research study to be carried out at a public middle-high School in Boquete, Panama. This regional school offered relevant conditions for the intervention and is representative for schools in the area: a diverse population, including students with a low socioeconomic level, low participation of parents, and a very high level of teenage pregnancy in the region. Data for this study were collected through interviews. Student participants in the MANW program were interviewed at pre and post implementation of the program at the school.

\subsection{The School-Based SEL Intervention}

MANW is a contextualized, middle-school based SEL-program with a focus on the promotion of Gender Equality. The program follows a socio-emotional learning framework [13], Teaching the Whole Child: Instructional Practices that Support SEL [23], and the guidelines for successful outcomes achievement: SAFE [14]. It refers to the sequenced training approach, the use of active learning methodologies to promote an experiential setting for new skills development, requiring focus on timing and attention, emphasizing the priority of skills development and an explicit conception of which specific socio-emotional skills the programs focuses on [14]. MANW is in part based on evidence-based health psychological theories that focus on the determinants of behavior and behavior change, in particular the Theory of Planned Behavior (TPB) [24]. The Gender Equality component of the program includes activities inspired by comparable life skills and gender equality programs [25-27]. Some of these programs focus on life skills such as self-esteem, communication, negotiation, problem-solving and assertiveness. The Capabilities Approach, enhancement of personal and inter-personal capacities towards gender equality, was paramount in the design of the program (Table A1). For a full description of the program's objectives and development, see [22]. 
The program consisted of 14 lessons of 90 min each, delivered over 4 months within the academic school year. It was implemented by class teachers who volunteered to participate in the research project. These teachers offered up the time allotted to regular curriculum hours and provided the MANW lessons instead of subject matters such as English, Geography, and Orientation. All the required materials of the program were distributed during every lesson by the teachers. Sessions were assessed by teachers and students through self-report questionnaires. The five components of SEL encouraged changes on three different gender behaviors [13]. Therefore, the learning activities of the program focused on these expected behavioral outcomes: Equal roles, which are related to "the responsibilities and tasks assigned to women, men, girls and boys. Like gender itself, gender roles can evolve over time, in particular through the empowerment of women and transformation of masculinities." [5]. Equal rights in relationships refers to practical ways to become aware and demand equal rights for women and men in personal relationships, recognizing and making institutions accountable for the respect and implementation of rights, as well as integrating it through school and home practices. Nonviolent problem solving refers to positive coping strategies to solve conflicts and negotiation skills.

The program includes activities to promote changes in socio-cognitive determinants of behavior derived from the Theory of Planned behavior, i.e., knowledge/awareness, attitude, skills and perceived social norms, which could elicit transformations towards gender equality. Knowledge is a cognitive factor, which allows misconceptions and myths to be disentangled from facts. Attitudes refer to the individual's positive or negative evaluation of the performance of the health behavior [28]. It allows evaluation of advantages and disadvantages, as well as perceived barriers and benefits of a certain behavior. For example, the positive or negative attitude towards practicing gender equality, in the case of students, will be influenced by the barriers, advantages, and disadvantages they may encounter that are established by social and cultural norms, and lived through experiences with peers, family, friends, boyfriends and girlfriends. Skills (social-emotional) refer to competencies such as negotiation skills, self-esteem, self-concept, decision-making and assertiveness [29]. Perceived social norms refer to parents', peers', and friends' beliefs about a certain behavior. Table A2 shows an overview of the program's lessons and expected outcomes.

\subsection{Participants}

Participants, 55 students in total (26 girls and 29 boys) from group 7th and 9th of middle-high school, were selected by the school. The criteria for the selection of the students was based on a prior 'high need' assessment conducted by the school administration and the leader teacher of the research project at the school, considering factors such as high risk of teenage pregnancy, violence, bulling, and the need to increase academic achievement. At baseline level 55 students were interviewed and at post-intervention level, 49 students were interviewed. Six students were excluded as they were not able to complete the program. Each group of students, group 7th and 9th received the program lessons in separate classrooms and groups. All students of both groups were allowed to participate in the program. Two teachers facilitated the program lessons in the groups. The age of students was between 12-15 years. Most participants indicated having a low socio-economic level, some living in extreme poverty.

\subsection{Implementers}

Teachers were the implementers of the program and were guided by a teacher's manual, which described the lessons and the design of the program. A school leader was selected by the administration of the school and was the contact person throughout the research project for all stakeholders (e.g., teachers, students, parents). Teachers receive $40 \mathrm{~h}$ of training (training of trainers/ToT) prior to implementing the program. This training emphasized that teachers first reviewed their own knowledge, views, assumptions, beliefs, and prejudices about gender and social-emotional skills. Furthermore, special attention was given to the acquirement of practical experience during the Tot, for example by role-playing, to ensure that teachers gained self-confidence and reduced potential 
resistance on the sensitive themes of the lessons. The ToT was based on a learner centered approach and the use of participatory and active learning methods.

\subsection{Research Instrument and Data Analysis}

Data were collected during fieldwork in Panama, July and November 2014. In depth, semi-structured interviews were conducted with the adolescents before and after the intervention. The interview protocol was based on the program's objectives, literature review, and theoretical frameworks (e.g., SEL, Theory of Planned Behavior). Interviews lasted from 20-30 min at pre-intervention, and about $45 \mathrm{~min}$ at post- intervention. Post-intervention interviews were carried out one week after the last lesson was completed.

Confidentiality and anonymity were ensured to participants: Participants were informed that they could end the interview if they wanted, without any explanation and at any given moment. Furthermore, at any sign of distress the interviewer terminated the interview. Interviews were recorded on written notes since participants preferred this method rather than audio recordings, but extensive notes taken during the interviews were verified with each respondent after the interview was concluded. Interviews were conducted in Spanish and translated into English by the first author, a Panamanian national who was sensitive to the social and cultural norms, as well as the economic and political conditions in this conservative context.

The transcripts were anonymized and stored on a password-protected personal computer. The researchers subsequently analyzed the transcripts line by line and coded them thematically. The coding scheme was similar to the topics in the interview protocol as the interviews were semi-structured, covering self-knowledge, knowledge/awareness of gender and gender equality, attitudes, skills, social and cultural norms and practices, agency, and intentions towards gender equality behaviors. The coding scheme also included intersectionalities between topics (e.g., agency, poverty, religion, and power relations). The data were analyzed using a directed content analysis approach [30]. This approach facilitated a categorization based on data derived from theory and relevant previous findings. An iterative coding process was used [31], which guaranteed that preliminary and inductively arrived coding categories were a reliable and accurate representation of the data content, which resulted in categories, which were further synthesized into overarching themes, presented in the results section. Table A3 shows an overview of the interview questions.

\section{Results}

The findings of this study reveal both the SEL competencies and the socio-cognitive determinants of behavior and behavior change in adolescents' perceptions of the program: knowledge, awareness, attitudes, skills/ self-efficacy, perceived social norms and intentions of participants as subcategories, regarding gender equal behaviors, which were grouped into three themes: Equal roles, equal rights in relationships, and nonviolent problem solving. Within these broader themes, categories can be identified (e.g., within equal gender roles, knowledge/awareness of the concept of gender and gender equality was one of the categories).

\subsection{Theme 1: Equal Gender Roles}

\subsubsection{Knowledge/Awareness}

At baseline, most participants defined gender as a word to describe types of music. Equality between women and men was described as an abstract concept that they might have heard of, but that they did not completely understand. Awareness of girls' and boys' roles in relationships, at home or school appeared to be biased by a "macho culture", social norms, religious beliefs, media, and school practices.

"As girls we are supposed to help at home and school. My mother does that too". (girl, 13 years) 
"Men are strong, and they bring the food to the family. Women take care of children and grandparents. They are sweet". (boy, 14 years)

The adolescents also mentioned that the consequences of early pregnancy were constant messages of current reproductive health educational curriculum and indicated differences between boys and girls in this respect. For example, most girls mentioned that they needed to invest more effort than boys in keeping love relationships, e.g., being more communicative and understanding of the needs of the boys.

"My boyfriend gets very upset many times, if I do not do what he wants. I always need to talk a lot with him and explain the situations". (girl, 15 years)

Frequently, girls were supposed to show "proof of love" (engaging in sexual encounters) to their boyfriends, in order not to lose them. In this sense, girls perceived pregnancy as an act of love. In contrast, more than half of the boys mentioned that they were 'supposed to' have girlfriends, and that early pregnancies were a consequence of these relationships.

Differences in roles for boys and girls also became apparent in the home setting, where most girls expressed that they were responsible to carry out household chores, while their brothers, fathers, and uncles were more allowed to enjoy other activities, e.g., play or watch television. Even though more than half of the girls expressed an interest using their time differently, accepting this as a normal fact of life was evident from their responses. At school, participants expressed that classroom chores were assigned to couples (girls and boys randomly), but the girls were mostly in charge of cleaning rooms, chalkboards, and general tasks. Boys also helped with those tasks, as well as making copies, bringing school materials, etc.

After the lessons, the majority of participants showed increased knowledge and awareness in gender, gender equality and its influence on ways to relate to each other. Participants stated that the MANW program was the first opportunity they had to explore these concepts and that they were now able to define them.

"Gender is not the way we are born, is learned and can be changed". (boy, 14 years)

\subsubsection{Attitudes}

Half of the participants described factors involved in gender role formations, mentioning religious beliefs, family values, and social norms as strong influences.

“I didn't know anything about my roles before. I just did what I was supposed to do to be a good girl, but yes, now I think more about all, we are not born with genders. Boys should listen and do more". (girl, 15 years)

However, analyzing these intersections was experienced as difficult by some participants. For example, they indicated that their religious beliefs were in conflict with the MANW program's lessons about gender, and these beliefs were difficult to overcome.

"We have learned now that women and men have the same rights and should also have the same opportunities, and it is ok, but the bible is very strict about our roles. We always talk about it at home". (boy, 12 years)

Early pregnancies were an issue mentioned by most participants, yet differently than before the intervention. At baseline, the majority of participants acknowledged that early pregnancies carry a heavy burden, especially for girls (e.g., dropping out school, shame, etc.). At post intervention, girls expressed that increasing their self-esteem and developing certain skills such as better decision-making, and negotiation helped them to be more aware of their own worth and choices, and especially how to communicate this to others. 
"I can make better decisions. If I want to achieve my goals and a boy asks me for a proof of love, I will say no, I am busy". (girl, 13 years)

Notably, whereas more than half of boys expressed that both girls and boys can make better decisions that benefit their own roles in personal relationships, they also indicated that early pregnancies can have a negative impact on boys, even though the expectation in a "machismo culture" is that boys are supposed to be strong and indifferent.

"If I make a girl pregnant, I am sure she will have a lot of problems. But I will be worried as well, even though that most people say boys are strong and it is not a big deal if that happens". (boy, 13 years)

"A man should be head of a family. But having a girl pregnant when I am young, means I will probably not be a good father. It is awful, I never had a father". (boy, 15 years)

Reflecting on their own roles in the household, and among family, friends, and school (relationships), nearly all participants expressed that the program provided a starting point for considering different views and seemed to forge new attitudes towards women and men's roles.

"I never helped at home in the past. Even though I do not like it, I try now to help my sisters more". (boy, 12 years)

"We are now trying to divide more the cleaning tasks at school, but some boys don't want to help. But the teacher is helping us and talk to the boys". (girl, 15 years)

When talking about masculinities, while still reflecting notions of patriarchy, the answers also indicated changes. More than half of boys expressed that family tasks could be more equally divided in the household, so that girls might have more time for other activities, such as playing, going out, or enjoying hobbies. Most girls expressed that skills development (referring to communication, negotiation, and assertiveness) had provided them for the first time with more self-confidence, to believe that they can share equally different roles in the household and relationships, and to make this a topic of discussion:

"I tell my mother often that my brothers should also help with the household chores. I feel that I can better communicate my ideas". (girl, 14 years)

"I believe that boys and girls have the same rights and can enjoy free time for hobbies or sports activities". (boy, 15 years)

The fact that a high percentage of families in Panama are headed by one member (mostly mothers or extended family members) seemed also to influence the gender perceptions of participants.

"I have now learned that men can cook and help in the house and with the family tasks. I have never had that at home. My father left us when I was very young, and my uncles say that women are for these kinds of tasks at home". (boy, 12 years)

\subsubsection{Skills/Self-Efficacy}

Developing critical thinking skills and increased empathizing with the opposite gender seemed to enhance a more positive attitude toward the importance of sharing equal roles and opportunities between women and men, and increased adolescents' introspection about their own roles and behaviors:

"I never had really to think so deep in my life. I believe that now I want to know more about who I am and what I can achieve with my life. We learned that we can achieve our dreams, through thinking carefully about our plan and actions. It was cool". (boy, 14) 
Furthermore, socio-economic conditions as poverty and lack of employment were often mentioned as factors that could create and reinforce gender role allocation and unequal power relations. Income generation seemed to be a very important issue for participants in terms of education and gender roles allocation. For example, the majority of participants stated that the participation of women in income generating activities could not only increase a sense of economic safety in the household, but also allow the payment for extra activities for family members and themselves (e.g., holidays, hobbies, sports). For the respondents, finishing high school was mentioned by students as a path towards achieving life goals, including income generation.

"Being economically independent will give me the freedom to have a better life. I need to finish high school, as I want to go to university and get a good job". (girl, 12 years)

"Women's income can help to pay bills in the house and give a nice life to your children". (boy, 15 years)

\subsubsection{Perceived Social Norms}

The agency dimension in better decision-making was evident on roles allocation. More than half of participants perceived the current gender model they experienced at home and school, as a barrier that limited them to express new ideas about gender roles or equality. Nearly half of the girls seemed less confident to be able to bring role changes at home in the context of household chores, negotiating time for pleasure activities, and participation in the community. Boys felt less comfortable to discuss equality of roles at home and in relationships. They were more worried about their masculinity profile and the opinion of parents and friends regarding a new way of approaching gender and equal roles. Most of them expressed that while they thought the accepted social norms on gender roles and identity were not correct, they thought it would require more time and opportunities to experience and develop personal capacities encouraging new forms of masculinity and femininity that could become socially accepted.

"I am not sure if I will be able to always express my opinion about our roles with my boyfriend, family or friends". (girl, 13 years)

"I am not sure what my uncle, father and grandfather who live with us will think if I start proposing new ways to divide our roles at home. Maybe they will think I am not really becoming a man, but I will try". (boy, 15 years)

\subsubsection{Intention}

Nevertheless, despite these hesitations, the majority of participants expressed that they would be willing to consider a more equal distribution of roles, whether in relationships, home or school, showing their positive intentions.

"I would definitely think about how to be fair to girls in a relationship. It is part of having equal roles between both of us". (boy, 15 years)

"I will definitely try and ask my parents to get more free-time at home to do other things than chores". (girl, 12 years)

\subsection{Theme 2: Equal Rights in Relationships}

\subsubsection{Knowledge/Awareness}

At baseline level, when asked about the rights of young people, the Human Rights Declaration and Children's Rights, the adolescents indicated they were aware of these and could list some of them. However, they were not familiar with specific international women rights' declarations or gender 
equality laws in Panama, nor what these entailed. Likewise, they lacked knowledge about places in the community where to report child abuse, and also indicated a low intention to look for help in case their rights were violated.

After the intervention, participants seemed to have become more aware of equal rights for women and men, in terms of work, equal share of roles, responsibilities, and opportunities. Furthermore, when probed, more than half of the adolescents were able to mention that equal rights also include the elimination of interpersonal and female-directed violence and the right for women to work, and respondents indicated awareness of the multiple barriers most women face in Panama.

The data showed that more than half of participants had gained more self-knowledge and self-worth after participating in the lessons, specifically regarding being more aware of their own qualities, possibilities, and especially about their rights. Some participants (around 21\%) showed less awareness, as they seemed less interested in these topics. A small group of participants (mainly girls, around $6 \%$ ) expressed to have prior knowledge on the personal capacities promoted by the program lessons and about their rights.

"I started to see myself differently, as someone with self-worth, who has rights and if I study, I can have a better life. I need to respect myself first, ask respect from others and defend my rights". (girl, 15 years)

"It is very good that everyone knows about their rights, especially to work. I have learned that girls and boys have the same self-worth and have the same rights. I don't think all children know that". (boy 12 years)

\subsubsection{Attitudes}

Most participants showed enthusiasm about being able to voice their opinions through the active learning experiences and participatory set-up of the program, especially on the issue of how they could use their voice to claim their rights.

"I believe now that we have rights as children or young people, but I think we have less opportunities to express our opinions. Sometimes, I try at home or school to say what I think. It is not always easy. But these lessons have helped". (girl, 15 years)

"I liked that we needed to play different roles during the lessons and see how gender is created in our culture and what people need to do. Rights for us exists, we need to use them". (girl, 14 years)

\subsubsection{Skills—Self-Efficacy}

Nevertheless, most girls felt they require more skills and opportunities to reject inequalities and ask for accountability. Further, they expressed that knowing their rights, and becoming skilled at claiming them, especially decision-making in their intimate relationships and in school, could create new opportunities to communicate and voice their worries and feelings.

"I need to communicate better to be able to express my opinions, especially at home and with friends/boyfriend. Sometimes is difficult if others think they know everything better". (girl, 15 years)

\subsubsection{Perceived Social Norms}

Half of the boys found challenging to talk with their friends and family about being gender sensitive and to have respect for the rights of girls and women. However, these existing social norms in their environment about the entitlements for women and men were perceived by participants as something that can be changed, but were likely difficult to change: 
"My father used to batter us (brothers and sisters) and my mother. Like if we did not have any rights. I do not think it is ok. It needs to change. We have to become better persons; we all have rights". (boy, 12 years)

Some of the boys (around 15\%) did not think it was possible to change current cultural and socially accepted gender norms. They expressed views on masculinity and femininity paradigms that seemed rigid and confused, especially about the fear of losing masculinity and acceptance among their peers and male family members if they would behave in a more gender-equal way. Some girls (around 10\%) also expressed their intention to behave in line with existing social norms, with regard to role sharing at home, or in relationships. They explained that that is the way their parents and their religious beliefs had taught them.

\subsubsection{Intention}

Asked about their intention to claim respect and rights in relationships and report abuse to the authorities in the future, most participants expressed that they did intend to be more communicative, and would try to find a trustful person to help them when they found themselves in such situations. More than half of the girls reported to be more willing to look for help when they would experience gender-based violence (physical/verbal), for example from a teacher. Boys mostly mentioned their intentions to report abuse perpetrated by their peer groups, as they in many cases did not see themselves as part of abuses, but also mentioned that going against some peer groups in the school is very dangerous and difficult.

"It is very difficult to try to ask respect for rights when you are in a big group. But I will try to look for help when I feel afraid of them or they are unfair". (boy, 12 years)

Interestingly, and possible inhibiting actual outreach in times of need, respondents indicated an overwhelming distrust of the authorities to reduce or handle complaints about the abuse of their rights:

“Over here, I don't think the police, or any other authority will help on cases of violence against girls or women". (girl, 15 years)

"I know women who have reported their husband or boyfriend because of violence and the police never did anything to stop it". (boy, 15 years)

\subsection{Theme 3: Nonviolent Problem Solving}

\subsubsection{Knowledge/Awareness}

At baseline measurement, more than half of the respondents mentioned the existence of violence and bullying at school. Girls seemed more affected by conflicts with other girls, as well as feeling annoyed by 'machismo' cultural jokes of boys regarding girls' bodies and behaviors, which in some cases were very aggressive. The use of violence, whether physical or emotional, was mentioned as the most likely way their peers would solve problems. Teachers were not mentioned as users of violence at school. However, respondents often mentioned to have experienced some verbal or physical violence at home. In this line, most participants were hesitant to talk about how to handle their problems, or how to deal with obstacles or decision-making in their personal relationships. Biased conceptions of violence and general statements such as 'men are violent by nature', 'women are fragile', 'violence sometimes is necessary', as well as 'battering children teaches obedience' were often raised by the adolescents as common and accepted forms to solve problems or conflicts in school, the home, or the society at large.

During the post-intervention interviews, most participants expressed that the program allowed them for the first time to become aware about sources of violence, especially against women, the influence of cultural norms - especially machismo - and how power relations in society and in their daily lives influence the behavior of boys, girls, women and men. 
"Women should not accept violence at all. There are other ways to solve problems, like talking instead of fighting". (girl, 15 years)

\subsubsection{Attitudes}

Half of the boys expressed that participating in the program allowed them to explore other views on masculinities and the use of violence than they were previously exposed to:

"I was told in my family that men have to be strong and violent, that it is our nature as men.

But I know now that I do not need to be violent". (boy, 15)

\subsubsection{Skills/Self-Efficacy}

Developing capacities (skills) to manage their emotions was the most common perceived positive change by the majority of participants. Half of the girls felt more confident to solve problems positively. Managing emotions was mentioned to avoid problems, and to enable searching for alternatives to solve conflict.

"I liked when we had a role-play about a boy who was very upset and threatening his girlfriend, so we could practice calming down, express our opinions, ask for respect and solve the problem without violence". (girl, 13 years)

Interestingly, boys seemed more prone to talk about strategies how to negotiate themselves and their social identities in a group of peers, and to avoid violence in such groups. They expressed having more self-confidence and feelings of worthiness can make them feel stronger to face challenges with other peers.

"If I love myself more, I will not get easy in trouble because I will think that I am very important and should not follow others who only like to make trouble". (boy, 12 years)

Other capacities like negotiation skills, assertiveness, self-respect, and effective communication (e.g., listen actively, showing empathy) were mentioned by more than half of the girls as ways to try to avoid violent practices and to achieve agency in their lives:

"I never knew how to say NO to anything. I feel now I can better say NO and manage to tell my friends or boyfriend when I do not like something. It is not easy, but I really feel I can do it". (girl, 15 years)

\subsubsection{Intention}

Most girls expressed that they intended not to accept violence from a boyfriend or others in the future. They seemed to be more aware of existing laws, where to go for help, and ways to solve problems without violence. More than half of boys expressed their intention to use positive alternatives to manage emotions and avoid violence in the arise of conflicts.

\section{Discussion}

The aim of this study was examining to what extent a school-based Socio-Emotional Learning program, Me and My New World, could evoke perceived changes towards gender equality beliefs and behaviors among young people in Panama. Specifically with regard to: equal roles, equal rights in relationships and nonviolent problem solving. We interviewed adolescents before and after participation.

Overall, participants expressed more positive opinions on gender and gender equality, increased knowledge about equal rights and nonviolent problem solving, as well as behaviors in line with these perceptions. Specifically, the intervention positively affected their awareness about gender equality, and increased positive attitudes and socio-emotional capacities, by improving their understanding of 
their own identities, agency, better managing their emotions, as well as increasing their self-confidence, communication, and decision-making and negotiation skills. These findings are in line with recent evidence highlighting the importance of students' self-reflection on their own and others' behaviors, which in turn could lead to alternatives to deal with sensitive issues as gender equality and its challenges [32]. In line with the determinants of behavior (change) identified in the Theory of Planned Behavior [24], the results indicate that the lessons of the program encouraged students' self-explorations of positive or negative evaluations of gender and gender equality (attitudes), and their beliefs regarding gender behaviors, as well as perceptions of important others' opinions and behaviors in this respect (i.e., social norms). Moreover, the respondents gave evidence of social emotional skills development (e.g., self-efficacy, negotiations skills, etc.), which could increase their intention towards more equal personal relationships and decisions. Further, the respondents indicated that the lessons of the MANW program provided them with insight into the benefits and barriers of practicing equal gender behaviors (e.g., equal roles, equal rights in relationships and non-violent problem solving). Specifically, considerations of cultural and social norms were repeatedly mentioned as a barrier in deconstructing gender inequalities (e.g., unequal role distribution, violence) arising in the daily lives of students. The focus of the program on inter- and intra-personal skills has enhanced participants' ways to see themselves, and the way they relate to each other. This result resonates with empirical evidence in Yemen, revealing the positive effects of a life skills program on adolescents' attitudes and beliefs towards themselves and their relationships with others [33].

Furthermore, the findings show that the program offered the adolescents new and safe spaces to try out alternative forms of gender roles, exploration of their gendered identities, and discussion about and enactment of different forms of masculinity and femininity. The theoretical principles upon which the MANW program is based ensured the use of active learning and effective behavioral change applications (e.g., role plays, diaries, etc.), specifically oriented towards the analysis of gender identity construction in society and daily life, the self, gender beliefs construction, and the precepts of masculinities and femininities; as well as attitudes and perceived barriers towards the use of gender equal behaviors in society. This result reinforces the importance of focusing on innovative educational strategies where young people can explore their own behavior. This is in line with recent evidence in Peru, highlighting the importance of different contexts, culture and social norms influencing adolescents' behavior, as well as the need for prevention efforts oriented to increase personal capacity development [34].

Furthermore, the results are in line with a growing literature showing the potential of SEL-programs in schools, for enhancing socio-cognitive determinants of behavior highlighted in the TPB, such as attitudes, perceived social norms, perceived behavioral control, self-efficacy and perceived barriers and benefits regarding gender equal behaviors, forging motivation, action and eventual behavioral changes $[14,24]$. The findings are also consistent with views stressing that individual behavior and choices are influenced by the socio-economic, cultural, and political context [35-37]. The interviews highlighted the multiple barriers and socio-emotional conditions young people face in the process of deconstructing and (re)classifying gender identities and behavior in the context of Panama, where conservative gender roles and machismo social norms prevail. Our study provides initial evidence for the potential of a SEL-based program in interlinking personal capacity development with the process of improving gender unequal beliefs and behaviors in relationships, and awareness of rights and opportunities.

Respondents' reflections showed that they first explored gender conceptualizations, searched for clarification of the self, and then analyzed the impact of social norms, culture, and religious beliefs on their relationships, as well as how roles and rights are operationalized in these relationships. The findings suggest that deliberations of own behavior, effect of actions on other people, and the significance of one's personal choice to make responsible decisions, offered a view to participants on the extension of opportunities that could be created towards gender equality behaviors, which could ultimately influence their relationships, health, and well-being. The process of mapping the resources 
and opportunities provided by parents, teachers, community, as well as the existent limitations in terms of culture, social norms, and religious beliefs, facilitated a consideration of different power relations and its implications for agency development and self-efficacy. As such, these findings corroborate the importance of focusing on the active role young people can play in fostering changes in their own life [38], and confirm similar research findings on the importance of increasing young people's skills and capacities to act on their rights [2].

\section{Implications and Limitations}

The respondents reported the struggle between identifying and considering new patterns of equal relationships between women and men, with the ingrained norms communicated in their machismo and patriarchal culture. The cultural context in which these young people's identities are forming poses limitations on young people's agency, participation, and voice, at school or at home. These findings are in line with DeJaeghere and Lee [39] who report evidence in Bangladesh emphasizing that lack of agency, gendered norms, and structures in communities that perpetuate discrimination can be difficult to overcome for young people, especially girls.

The results highlight the importance of individual capacities development of all stakeholders in the educational system, transforming existing paradigms surrounding gender in educational institutions, curriculum, and practices. Likewise, several vital factors such as uncertainty about support at home, distrust in public institutions and authorities to help them, teachers' and peer's (negative) views towards gender equality behaviors, as well as poverty and social conditions, remain influencing the intention of young people, to try out new gender equality realities. The interconnectedness of the contexts in which adolescents live, and the social norms that permeate these contexts, emphasizes the importance of the "whole school approach" within the SEL perspective, which includes a work alliance between the students, school, parents and the community [14].

Interestingly, while education does not guarantee job allocation or income generation, most students seemed more motivated to embrace gender equality behaviors if women's rights to work and gain income would mean creating better socio-economic conditions for the household. This highlights the notion that economic changes might influence faster material arrangements between women and men [10]. Further, boys often considered negative consequences of early pregnancy not only for girls, but also for themselves, even though they indicated that they felt they were expected to follow normative "macho" behavior in relationships, especially regarding early pregnancies. This finding is similar to recent evidence in Paraguay, where young boys' personal behavior often differs from current masculinity and normative in their neighborhoods [40]. Therefore, it is vital to include boys' and men's voices in developing health promotion programs.

Several limitations of the current study should be acknowledged. First, the MANW program was implemented only once in the school curriculum, without a control group. We cannot say whether the changes reported by the adolescents were due to the program, or the result of processes/factors we did not take into account. Moreover, these changes are adolescents' perceptions of the effect of the program, and our results should be verified in follow-up (quantitative) research that includes a control group. Since the post-intervention interviews were conducted relatively soon after the adolescents finished the last lesson, we cannot say whether these changes are sustainable and will last for longer periods of time. However, it is important to emphasize that this study, through qualitative methods (interviews), has allowed to gain in-depth insights into youths' lives, needs and experiences in Panama, especially voicing their opinions on gender equality sensitive issues. Furthermore, the findings of this study revealed the concerns and limitations of boys and girls with respect to which strategies could be more effective in their contexts to initiate and sustain gender equal relationships and practices, as well as, how their perceived social norms (acceptance or rejection within peer groups) regarding gender equal behaviors, could limit or enhance their future performance of behaviors. These potential issues, highlighting the differing nature of responses and views from boys and girls, could be addressed in future research of SEL and Gender Equality program's design and implementation. 


\section{Conclusions}

The findings of this study suggest that a school-based program using Social-Emotional Learning (SEL), which seeks to enhance cognitive and psychosocial capacities of students, could be an appealing educational strategy to introduce new strategies to change young people's perceptions of and behaviors towards gender equality. Such a program can facilitate steps to transform biased gender identities, challenge assumptions of inequalities, emphasize agency development, and increases the spectrum of action and participation of young people in important domains of their lives. In line with the UN Sustainable Development Goals (SDG), as well as international health and well-being agendas for young people, achieving enacted gender equality calls for efforts towards a new perspective on the type of life women and men value. Since gender equality is the ultimate achievement of this process, special attention must be given to potential strategies that embrace gender equality as part of the daily educational experiences and practices of young people.

Author Contributions: A.B.A.L., K.M. and G.K. conceptualized the methods and theoretical basis of the manuscript. A.B.A.L. collected and analyzed data. A.B.A.L. and K.M. further analyzed, interpreted and discussed data and wrote results. A.B.A.L. drafted manuscript, K.M. and G.K. additionally wrote sections. A.B.A.L., K.M., and G.K. were involved in revising the manuscript after peer review. All authors have read and agreed to the published version of the manuscript.

Funding: No funding was obtained.

Conflicts of Interest: Authors declare no conflict of interest.

\section{Appendix A}

Table A1. Capabilities and Expected Behavioral Outcomes (BO) of the program Me and My new World.

\begin{tabular}{cc}
\hline Main Areas of Expected Behavioral Outcomes (BO) & Selected Capabilities (*) \\
\hline Equal Gender Roles & $\begin{array}{c}\text { Practical reason to promote equal gender roles, relates to the } \\
\text { capability of "being able to form a conception of the good and } \\
\text { to engage in critical reflection about the planning of one's life" } \\
\text { (Nussbaum, 2012). In this line, the MANW/ SEL program } \\
\text { emphasizes critical analysis of gender roles allocation and } \\
\text { identity development, including the intersections of culture, } \\
\text { family values, social norms, and media influence }\end{array}$ \\
$\begin{array}{c}\text { Affiliation and Voice are intrinsically related to being able to } \\
\text { claim rights. It emphasizes the social basis of self-respect and } \\
\text { non- humiliation, as well as being able to be treated as a } \\
\text { dignified being whose worth is equal to that of others } \\
\text { (Nussbaum, 2011). This entails provisions of } \\
\text { Defending one's rights } \\
\text { non-discrimination on the basis of race, sex, sexual orientation, } \\
\text { ethnicity, caste, religion, national origin. In addition, being } \\
\text { treated with respect and dignity is related to having voice. } \\
\text { It should also imply "having freedom to participate, to be } \\
\text { taken seriously, and have their opinion valued and heard" } \\
\text { (Loots \& Walker, 2015) }\end{array}$ \\
$\begin{array}{c}\text { Bodily Integrity is related to "being able to move freely from } \\
\text { place to place; being free of harassment and to be secure } \\
\text { against violent assault, including sexual assault and domestic } \\
\text { violence" (Nussbaum, 2011). The MANW program } \\
\text { highlighted the importance of self-esteem, self-concept and } \\
\text { self-confidence to avoid abuses and to acquire positive, } \\
\text { non-violence strategies to manage emotions and problems. }\end{array}$ \\
Nonviolent problem solving
\end{tabular}

* Adjusted from Alkire (2008) capability procedural system. 
Table A2. Overall content of the MANW program lessons.

\begin{tabular}{|c|c|c|}
\hline $\begin{array}{l}\text { Social-Emotional } \\
\text { Competencies/Lessons }\end{array}$ & $\begin{array}{l}\text { Social-Emotional Competencies } \\
\text { and Gender Equality Concepts }\end{array}$ & Topics \\
\hline \multicolumn{3}{|l|}{ Module 1. Self -Awareness } \\
\hline Session 1. But, Who am I? & $\begin{array}{l}\text { Introduction to the program, } \\
\text { self-awareness, interest, values } \\
\text { and strengths, critical thinking. }\end{array}$ & $\begin{array}{l}\text { Students explore identity development, gender and } \\
\text { roles allocation; discover their self-concept and } \\
\text { increase critical thinking. }\end{array}$ \\
\hline Session 2. My feelings and me & $\begin{array}{l}\text { Identification of emotional } \\
\text { changes during adolescence, } \\
\text { self-esteem, decision- making. }\end{array}$ & $\begin{array}{l}\text { Students discuss self-esteem and its links with } \\
\text { gender, how it is developed, connections with } \\
\text { emotional changes during adolescence and the } \\
\text { significance of decision making to manage } \\
\text { better decisions. }\end{array}$ \\
\hline Session 3. Playing the roles & $\begin{array}{l}\text { Gender, gender roles, } \\
\text { masculinities, femininities, } \\
\text { empathy. }\end{array}$ & $\begin{array}{l}\text { Discuss boys and men's socialization, gender norms } \\
\text { and stereotypes; take the perspective of others; reflect } \\
\text { on different gender roles, rights. }\end{array}$ \\
\hline Session 4. My body, my say & $\begin{array}{l}\text { Problem solving skills, self-efficacy } \\
\text { and self-esteem. Own strength } \\
\text { and limitations (physical) }\end{array}$ & $\begin{array}{l}\text { Body image and adolescence, its influence on the } \\
\text { way they feel and act; learn strategies to analyze and } \\
\text { search for solutions. }\end{array}$ \\
\hline \multicolumn{3}{|l|}{ Module 2. Self- Management } \\
\hline $\begin{array}{l}\text { Session } 5 \text {. Power relations } \\
\text { and ME }\end{array}$ & $\begin{array}{l}\text { Gender violence, power relations, } \\
\text { assertiveness. }\end{array}$ & $\begin{array}{l}\text { Discuss the theory of power, power relations and its } \\
\text { intersections with gender violence and abuse of } \\
\text { rights; follow steps to make assertive decisions and } \\
\text { learn to say NO. }\end{array}$ \\
\hline Session 6. Are these my rights? & Goal setting and monitoring. & $\begin{array}{l}\text { Become aware of their diversity on needs, rights and } \\
\text { the capacities they require to achieve goals and } \\
\text { overcome obstacles. Set goals and } \\
\text { monitoring strategies. }\end{array}$ \\
\hline Session 7. I am in control & $\begin{array}{l}\text { Recognizing and analyzing } \\
\text { emotions through a gender } \\
\text { perspective. }\end{array}$ & $\begin{array}{l}\text { Recognize own emotions and they ways they have } \\
\text { learnt to express it due to their genders; } \\
\text { communication; connections with violence } \\
\text { and abuses. }\end{array}$ \\
\hline $\begin{array}{l}\text { Session } 8 \text {. Gender } \\
\text { Based Violence }\end{array}$ & $\begin{array}{l}\text { Emotions regulations, impulses, } \\
\text { coping with stress. }\end{array}$ & $\begin{array}{l}\text { Learn strategies how to manage negative emotions in } \\
\text { a positive way, and steps to handle } \\
\text { stressful situations. }\end{array}$ \\
\hline \multicolumn{3}{|l|}{ Module 3. Social Awareness } \\
\hline Session 9. What about my life? & $\begin{array}{l}\text { Pregnancy } 4 \text { boys and girls. } \\
\text { Respect for themselves and } \\
\text { for others. }\end{array}$ & $\begin{array}{l}\text { Students reflect on the pressures related to unwanted } \\
\text { teenage pregnancies and responsibilities of both boys } \\
\text { and girls; connection between decision making, } \\
\text { self-esteem and self-concept. }\end{array}$ \\
\hline $\begin{array}{l}\text { Session } 10 \text {. Friendship } \\
\text { and relationship }\end{array}$ & $\begin{array}{l}\text { People in your life, empathy, } \\
\text { managing peer pressure. }\end{array}$ & $\begin{array}{l}\text { Explore how gender norms, beliefs and values } \\
\text { influence friendships and personal relationships; } \\
\text { defend their rights and limits; learn how to resist } \\
\text { individual or group pressure. }\end{array}$ \\
\hline Session 11 . I negotiate my way & $\begin{array}{l}\text { Negotiation skills, } \\
\text { critical thinking. }\end{array}$ & $\begin{array}{l}\text { Learn different techniques to negotiate difficult } \\
\text { situations in daily life (with friends, school, home) }\end{array}$ \\
\hline \multicolumn{3}{|l|}{$\begin{array}{l}\text { Module } 4 . \\
\text { Relationship skills }\end{array}$} \\
\hline $\begin{array}{l}\text { Session } 12 . \text { Did you get what } \\
\text { I mean? }\end{array}$ & Effective communication. & $\begin{array}{l}\text { Discuss effective ways to how can they express their } \\
\text { opinion, ideas, needs, preferences; active listening. }\end{array}$ \\
\hline $\begin{array}{l}\text { Session } 13 \text { Girls and boys act } \\
\text { for change }\end{array}$ & Problem solving. & $\begin{array}{l}\text { Learn strategies to be an active bystander and know } \\
\text { who and where to go in need of support. Provide } \\
\text { help when needed }\end{array}$ \\
\hline \multicolumn{3}{|l|}{$\begin{array}{l}\text { Module 5. Responsible } \\
\text { decision making }\end{array}$} \\
\hline $\begin{array}{l}\text { Session } 14 . \text { Your dreams, } \\
\text { your future }\end{array}$ & $\begin{array}{l}\text { Life plan development with } \\
\text { gender equality perspective, } \\
\text { responsible decision making, } \\
\text { creative thinking }\end{array}$ & $\begin{array}{l}\text { Use creativity to set a plan focusing on using the } \\
\text { capacities learnt during the program, as to achieve } \\
\text { their goals (e.g., finishing school and have respectful } \\
\text { and healthy relationships). }\end{array}$ \\
\hline
\end{tabular}


Table A3. Sample of Interview questions/Effects program evaluation.

\begin{tabular}{|c|c|c|c|c|c|}
\hline $\begin{array}{l}\text { Outcomes } \\
\text { Behavior }\end{array}$ & $\begin{array}{l}\text { Determinants } \\
\text { Knowledge/Awareness }\end{array}$ & Attitudes & Skills/Self-Efficacy & Perceived Social Norms & Intention \\
\hline $\begin{array}{l}\text { Equal gender } \\
\text { roles }\end{array}$ & 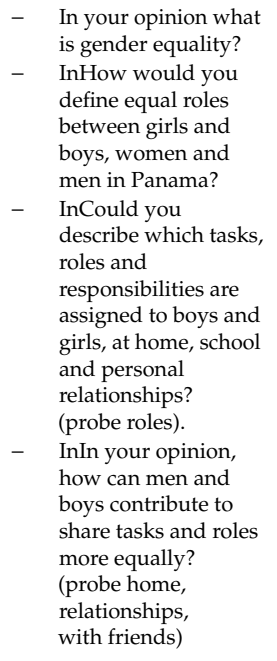 & 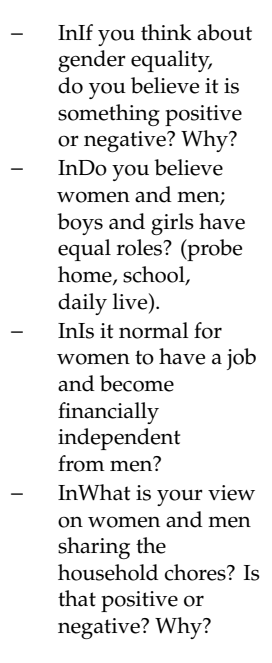 & $\begin{array}{l}\text { - InHow is for you } \\
\text { to talk and } \\
\text { practice gender } \\
\text { equality and } \\
\text { equal gender } \\
\text { roles? (probe } \\
\text { with parents, } \\
\text { school, } \\
\text { boyfriend/ } \\
\text { girlfriend, with } \\
\text { friends). }\end{array}$ & $\begin{array}{l}\text { - InWhat do your } \\
\text { friends think about } \\
\text { gender equality? } \\
\text { - } \quad \text { InWhat do your } \\
\text { parents think about } \\
\text { gender equality? }\end{array}$ & $\begin{array}{l}\text { - InDo you } \\
\text { plan in the } \\
\text { future to } \\
\text { promote and } \\
\text { practice } \\
\text { gender } \\
\text { equality? } \\
\text { (probe roles, } \\
\text { rights and } \\
\text { use of } \\
\text { nonviolence). }\end{array}$ \\
\hline $\begin{array}{l}\text { Equal rights in } \\
\text { relationships }\end{array}$ & 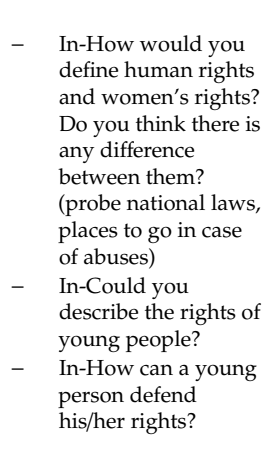 & 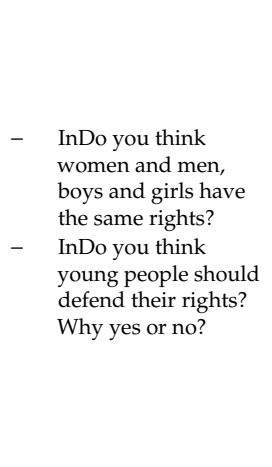 & $\begin{array}{ll}\text { - } & \text { InDo you feel } \\
\text { you can talk } \\
\text { about your rights } \\
\text { with your } \\
\text { parents, friends } \\
\text { and teachers? } \\
\text { - } \quad \text { InDo you feel } \\
\text { you can negotiate } \\
\text { with your } \\
\text { partner to wait } \\
\text { until you are } \\
\text { prepared for to } \\
\text { become a parent? } \\
\text { InDo you feel } \\
\text { comfortable to } \\
\text { say no and report } \\
\text { any abuses? }\end{array}$ & $\begin{array}{l}\text { - InDo you feel you } \\
\text { would be supported } \\
\text { if you approach any } \\
\text { institution for help, } \\
\text { information about } \\
\text { rights or to report } \\
\text { gender violence? } \\
\text { (probe ombudsman, } \\
\text { police, school } \\
\text { counseling, parents) }\end{array}$ & \\
\hline $\begin{array}{l}\text { Nonviolent } \\
\text { problem-solving }\end{array}$ & $\begin{array}{ll}\text { - } & \text { In-How would you } \\
\text { define } & \text { gender violence? } \\
\text { - } \quad \text { InCan you mention } \\
\text { steps to problems in } \\
\text { a positive way? } \\
\text { - InHow would you } \\
\text { define emotions? } \\
\text { How are they related } \\
\text { to violence? }\end{array}$ & $\begin{array}{l}\text { - InWhat do you think } \\
\text { about violence } \\
\text { against women } \\
\text { and girls? } \\
\text { - InIn your opinion, } \\
\text { could young people } \\
\text { promote ways of } \\
\text { living without } \\
\text { violence? (probe } \\
\text { personal } \\
\text { relationships, } \\
\text { friendship, school). }\end{array}$ & $\begin{array}{ll}\text { - } & \text { InDo you feel } \\
\text { able to say NO } \\
\text { against any kind } \\
\text { of violence? } \\
\text { - } \quad \text { InAre you able to } \\
\text { manage your } \\
\text { emotions and } \\
\text { impulses? If yes, } \\
\text { how? (probe } \\
\text { situations related } \\
\text { to anger). } \\
\text { InCan you solve } \\
\text { your problems in } \\
\text { positive ways? } \\
\text { (probe different } \\
\text { forms of } \\
\text { nonviolent } \\
\text { problem solving). }\end{array}$ & $\begin{array}{l}\text { - InWhat do your } \\
\text { friends and parents } \\
\text { think about } \\
\text { gender violence? } \\
\text { - } \quad \text { InWhat do your } \\
\text { parents, friends think } \\
\text { about using } \\
\text { nonviolence to } \\
\text { solve problems? }\end{array}$ & \\
\hline
\end{tabular}

\section{References}

1. Unterhalter, E. Gender Equality, Education and the Capability Approach. In Sen's Capability Approach and Social Justice in Education; Walker, M., Unterhalter, E., Eds.; Palgrave: London, UK, 2007; pp. 87-107.

2. Loots, S.; Walker, M. Shaping a gender equality policy in higher education: Which human capabilities matter? Gen. Educ. 2015, 27, 361-375. [CrossRef]

3. Manandhar, M.; Hawkes, S.; Buse, K.; Nosratid, E.; Magar, V. Gender, Health and the 2030 Agenda for Sustainable Development. Bull. World Health Organ. 2018, 96, 644-653. [CrossRef] [PubMed]

4. Robeyns, I. Three models of education: Rights, capabilities and human capital. Theory Res. Educ. 2006, 4, 69-84. [CrossRef] 
5. European Institute for Gender Equality. Glossary of Terms. Available online: https://eige.europa.eu/gendermainstreaming/concepts-and-definitions (accessed on 18 July 2020).

6. Malhotra, A.; Sidney, S.; Boender, C. Measuring Women's Empowerment as a Variable in International Development; World Bank Gender and Development Group and World Bank Social Development Group: Washington, DC, USA, 2002.

7. Cornwall, A.; Rivas, A. From 'gender equality and women's empowerment' to global justice: Reclaiming a transformative agenda for gender and development. Third World Q. 2015, 36, 396-415. [CrossRef]

8. Ministerio de Salud (MINSA). Proporción de Adolescentes Embarazadas, Enero a Noviembre 2017; Proportion of Pregnant Teenagers, January to November 2017; Ministry of Health of Panama: Panama City, Panama, 2017.

9. Dholakia, J.; Buchanan, R.; Nash, W. Multifaceted Adolescent Reproductive Health Education Strategies in Panama. J. Glob. Health 2012, 2, 21-26. Available online: https://www.ghjournal.org/adolescent-reproductivehealth-education-strategies-in-panama/ (accessed on 19 July 2020).

10. Ridgeway, C. Framed by Gender: How Gender Inequality Persists in the Modern World; Oxford University Press: Oxford, UK, 2011.

11. DeJaeghere, J. Public Debate and Dialogue from a Capabilities Approach: Can it Foster Gender Justice in Education? J. Hum. Dev. Cap. 2012, 13, 353-371. [CrossRef]

12. Vaughn, R. Gender Equality and Education in the Sustainable Development Goals. Background Paper Prepared for the 2016 Global Education Monitoring Report 2016; UNESCO: Paris, France, 2016; Available online: https://en.unesco. org/gem-report/report/2016/education-people-and-planet-creating-sustainable-futures-all (accessed on 12 July 2020).

13. Collaborative for Academic, Social, and Emotional Learning (CASEL). Effective Social and Emotional Learning Programs (Preschool and Elementary School Edition); CASEL: Chicago, IL, USA, 2012.

14. Durlak, J.A.; Weissberg, R.P.; Dymnicki, A.B.; Taylor, R.D.; Schellinger, K. The Impact of Enhancing Students' Social and Emotional Learning: A Meta-Analysis of School-Based Universal Interventions. Child Dev. 2011, 82, 405-432. [CrossRef]

15. Coelho, V.A.; Sousa, V. Comparing Two Low Middle School Social and Emotional Learning Program Formats: A Multilevel Effectiveness Study. J. Youth Adolesc. 2016, 46, 656-667. [CrossRef]

16. Wigelsworth, M.; Lendrum, A.; Oldfield, J.; Scott, A.; ten Bokkel, I.; Tate, K.; Emery, C. The impact of trial stage, developer involvement and international transferability on universal social and emotional learning programme outcomes: A meta-analysis. Cam. J. Educ. 2016, 46, 347-376. [CrossRef]

17. Coehlo, V.; Marchante, M.; Sousa, V. Positive Attitude: A multilevel analysis of the effectiveness of a social and emotional learning program for Portuguese middle school students. J. Adolesc. 2015, 43, 29-38. [CrossRef]

18. Kimber, B.; Sandell, R.; Bremberg, S. Social and emotional training in Swedish classrooms for the promotion of mental health: Results from an effectiveness study in Sweden. Health Promot. Int. 2008, 23, 134-143. [CrossRef] [PubMed]

19. Walker, M. Imagining STEM higher education futures: Advancing human well-being. Health Educ. 2015, 70, 417-425. [CrossRef]

20. Durrani, N. Schooling the other: The representation of gender and national identities in Pakistani curriculum texts. Comp. J. Comp. Int. Educ. 2008, 38, 595-610. [CrossRef]

21. Stromquist, N. Gender, Education and the possibility of Transformative Knowledge. Comp. J. Comp. Int. Educ. 2006, 36, 145-161. [CrossRef]

22. Araúz Ledezma, A.B.; Massar, K.; Kok, G. Behavioural and environmental influences on adolescent decision making in personal relationships: a qualitative multi-stakeholder exploration in Panama. Health Educ. Res. 2020, 35, 1-14. [CrossRef]

23. Yoder, N. Teaching the Whole Child: Instructional Practices that Support SEL in Three Teacher Evaluation Frameworks; Revised Edition; Center on Great Teachers and Leaders at American Institutes for Research: Washington, DC, USA, 2014. Available online: https://gtlcenter.org/sites/default/files/TeachingtheWholeChild.pdf (accessed on 13 July 2020).

24. Fishbein, M.; Ajzen, I. Predicting and Changing Behavior. The Reasoned Action Approach; Psychology Press, Taylor and Francis Group: New York, NY, USA, 2010.

25. Butterfly Works; One World UK; Action Health Incorporated; FLHE Program and NERDC. Learning about Living (LAL) Program; Butterfly Works: The Netherlands; One World: UK; Action Health Incorporated: Nigeria; FLHE Program and NERDC: Lagos, Nigeria, 2009. 
26. Ricardo, C.; Nascimento, M.; Fonseca, V.; Segundo, M. Program H and Program M: Engaging Young Men and Empowering Young Women to Promote Gender Equality and Health; Promundo and PAHO: Washington, DC, USA, 2010.

27. Rutgers. The World Start with Me (WSWM) Program; Rutgers: Utrecht, The Netherlands, 2013.

28. Ajzen, I. Attitudes, Personality and Behaviour; Dorsey Press: Chicago, IL, USA, 1988.

29. Payton, J.W.; Wardlaw, D.M.; Graczyk, P.A.; Bloodworth, M.R.; Tompsett, C.J.; Weissberg, R.P. Social and emotional learning: A framework for promoting mental health and reducing risk behavior in children and youth. J. Sch. Health 2000, 70, 179-185. [CrossRef]

30. Hsieh, H.F.; Shannon, S.E. Three approaches to qualitative content analysis. Qual. Health Res. 2005, 9, 1277-1288. [CrossRef]

31. Mayring, P. Qualitative Content Analysis. Basics and Techniques, 12th ed.; BeltzVerlag: Weinheim, Germany, 2010.

32. Dür, M.; Keller, L. Education for Sustainable Development through International Collaboration. A Case Study on Concepts and Conceptual Change of School-Students from India and Austria on Gender Equality and Sustainable Growth. Educ. Sci. 2018, 8, 187. [CrossRef]

33. Al-Iryani, B.; Basaleem, K.A.; Crutzen, R.; Kok, G.; van den Borne, B. Evaluation of a School-Based HIV prevention Intervention for Yemeni Adolescents. BMC Public Health 2011. [CrossRef]

34. Salazar, X.; Cáceres, C.; Rosasco, A.; Kegeles, S.; Maiorana, A.; Gárate, M.; Coates, T. Vulnerability and sexual risks: Vagos and vaguitas in a low-income town in Peru. Cult. Health Sex. 2005, 7, 375-387. [CrossRef]

35. Bartholomew, L.K.; Markham, C.; Ruiter, R.; Fernandez, M.E.; Kok, G.; Parcel, G. Planning Health Promotion Programs. An Intervention Mapping Approach, 4th ed.; Jossey-Bass: San Francisco, CA, USA, 2016.

36. Kok, G.; Gottlieb, N.H.; Panne, R.; Smerecnik, C. Methods for environmental change; an exploratory study. BMC Public Health 2012, 12, 1037. [CrossRef] [PubMed]

37. Rijsdijk, L.E.; Bos, A.E.R.; Ruiter, R.A.C.; Leerlooijer, J.N.; de Haas, B.; Schaalma, H.P. The World Starts with Me: A multilevel evaluation of a comprehensive sex education programme targeting adolescents in Uganda. BMC Public Health 2011, 11, 334. [CrossRef]

38. Biggeri, M.; Santi, M. The Missing Dimensions of Children's Well-being and Well-becoming in Education Systems: Capabilities and Philosophy for Children. J. Hum. Dev. Cap. 2012, 13, 373-395. [CrossRef]

39. DeJaeghere, J.; Lee, S.K. What matters for Marginalized Girls and Boys in Bangladesh: A capabilities approach for understanding educational well-being and empowerment. Res. Comp. Int. Educ. 2011, 6, $27-42$. [CrossRef]

40. Fleming, P.J.; Andes, K.L.; DiClemente, R.J. But I'm not like that: Young men's navigation of normative masculinites in a marginalised urban community in Paraguay. Cult. Health Sex. 2013, 15, 652-666. [CrossRef] [PubMed]

(C) 2020 by the authors. Licensee MDPI, Basel, Switzerland. This article is an open access article distributed under the terms and conditions of the Creative Commons Attribution (CC BY) license (http://creativecommons.org/licenses/by/4.0/). 